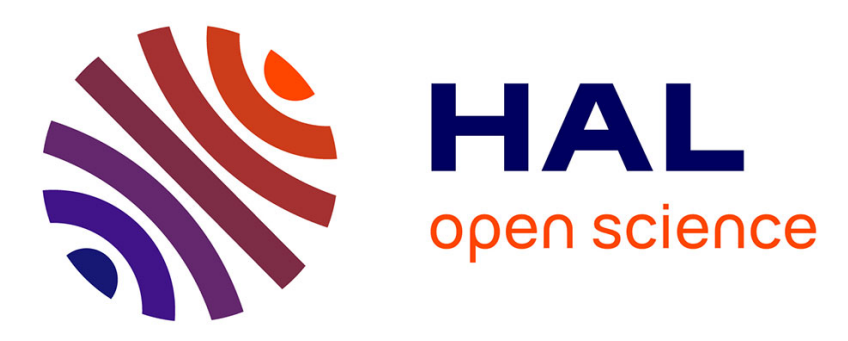

\title{
Identification and antioxidant characterisation of thioredoxin-like1 from Apis cerana cerana
}

Wenjing Lu, Mingjiang Kang, Xiufang Liu, Xiaocui Zhao, Xingqi Guo, Baohua Xu

\section{- To cite this version:}

Wenjing Lu, Mingjiang Kang, Xiufang Liu, Xiaocui Zhao, Xingqi Guo, et al.. Identification and antioxidant characterisation of thioredoxin-like1 from Apis cerana cerana. Apidologie, 2012, 43 (6), pp.737-752. 10.1007/s13592-012-0148-7 . hal-01003669

\section{HAL Id: hal-01003669 \\ https://hal.science/hal-01003669}

Submitted on 1 Jan 2012

HAL is a multi-disciplinary open access archive for the deposit and dissemination of scientific research documents, whether they are published or not. The documents may come from teaching and research institutions in France or abroad, or from public or private research centers.
L'archive ouverte pluridisciplinaire HAL, est destinée au dépôt et à la diffusion de documents scientifiques de niveau recherche, publiés ou non, émanant des établissements d'enseignement et de recherche français ou étrangers, des laboratoires publics ou privés. 


\title{
Identification and antioxidant characterisation of thioredoxin-like1 from Apis cerana cerana
}

\author{
Wenjing $\mathrm{Lu}^{1}$, Mingjiang $\mathrm{KANG}^{2}$, Xiufang $\mathrm{LIU}^{1}$, Xiaocui $\mathrm{ZHAO}^{1}$, Xingqi Guo ${ }^{1}$, \\ Baohua $\mathrm{Xu}^{2}$ \\ ${ }^{1}$ State Key Laboratory of Crop Biology, College of Life Sciences, Shandong Agricultural University, Taian, \\ Shandong 271018, People's Republic of China \\ ${ }^{2}$ College of Animal Science and Technology, Shandong Agricultural University, Taian, Shandong 271018, People's \\ Republic of China
}

Received 12 January 2012 - Revised 3 May 2012 - Accepted 24 May 2012

\begin{abstract}
Thioredoxins (Trxs) play a crucial role in maintaining redox homeostasis and protecting organisms against toxic reactive oxygen species. Compared with the well-studied Trxs in Mammalia, little is reported in insects. In this study, we isolated a Trx-likel gene from Apis cerana cerana (AccTrx-likel), a single copy gene, and characterised its antioxidant activity. Quantitative real-time PCR and immunohistochemical assays revealed that AccTrx-like1 was most highly expressed in larvae and was localised primarily in the epidermis and brain tissue of adults. Expression analyses indicated that AccTrx-likel expression is induced by both $\mathrm{H}_{2} \mathrm{O}_{2}$ and low temperatures. Moreover, catalase activity and malondialdehyde levels were inversely related to the expression levels of AccTrxlikel in honeybee injected with $\mathrm{H}_{2} \mathrm{O}_{2}$ at $30 \mathrm{~min}$. Taken together, these results suggest that AccTrx-likel is an important antioxidant gene that is likely to play a role in preventing oxidative stress in A. cerana cerana.
\end{abstract}

\section{Trx-like1 / Apis cerana cerana / quantitative real-time PCR / oxidative stress}

\section{INTRODUCTION}

"Reactive oxygen species (ROS)" is a collective term for $\mathrm{H}_{2} \mathrm{O}_{2}$ and oxygen radicals, including superoxide $\left(\mathrm{O}_{2}^{-}\right)$, hydroxyl $(\mathrm{OH} \cdot)$ and hydroperoxyl $\left(\mathrm{HO}_{2} \cdot\right)$ radicals. ROS actively participate in a diverse array of biological processes that include programmed cell death and the induction and maintenance of the transformed state (Finkel 2003). Excessive ROS lead to oxidative stress, which may be induced by external or internal factors and can damage cellular macromolecules, such as nucleic acids, proteins and lipids. This damage interferes with normal cellular functions and

Corresponding author: X. Guo, xqguo@sdau.edu.cn; B.Xu,bhxu@sdau.edu.cn

Manuscript editor: Klaus Hartfelder can ultimately lead to cell death (Tsuda et al. 2010). Of the many biological targets for oxidative stress, lipids are the most often affected (Del et al. 2005). Lipid oxidation results in the generation of many harmful secondary products, such as malondialdehyde (MDA), which can interfere with the sensitive mechanisms involved in cell functionality. Relatively low or high environmental temperatures have also been shown to induce oxidative stress accompanied by a high level of lipid peroxidation (Yang et al. 2010). In addition, oxidative stress generates a number of superoxide radicals, which act as oxidants or reductants and result in the production of hydroxyl radicals (Lopez-Martinez et al. 2008). Typically, superoxide radicals are converted to $\mathrm{H}_{2} \mathrm{O}_{2}$, and catalase (CAT) then reduces $\mathrm{H}_{2} \mathrm{O}_{2}$ to water and molecular oxygen (Schwarze et al. 1998). Hydroxyl radicals, which 
are believed to be the main species responsible for oxidative damage, are formed if $\mathrm{H}_{2} \mathrm{O}_{2}$ cannot be eliminated (Fridovich 1978; Halliwell and Gutteridge 1984). In order to defend against the miscellaneous environmental oxidative stresses, social insects have evolved an autologous antioxidant system that includes a series of enzymes and non-enzymatic molecules (Evans et al. 2006). This endogenous antioxidant system (Tanaka et al. 2002) includes thioredoxin (Trx), thioredoxin peroxidase and thioredoxin reductase. Trx-dependent peroxidase, also known as peroxiredoxin, belongs to the Trx family.

Trxs are small, highly conserved oxidoreductase proteins required to maintain the redox homeostasis in many physiological cellular processes (Zhang et al. 2008; Gromer et al. 2004). Trx was first identified as an electron donor for ribonucleotide reductase in Escherichia coli (Laurent et al. 1964). An amino acid sequence (Cys-Gly-Pro-Cys) was later found to be linked to the conserved Trx active site, wherein the cysteine residues undergo reversible oxidation between the dithiol and disulfide forms (Jiménez et al. 2006). Seven Trx or Trx-like proteins have been identified in mammals, in which both tissue-specific and ubiquitously expressed forms have been characterised. Spyrou et al. (1997) reported the localisation of Trx 2 within mitochondria in rat heart tissue. Sptrx (sperm-specific Trx) was the first Trx with a tissue-specific distribution to be studied in humans (Miranda-Vizuete et al. 2001), where it is expressed exclusively in spermatozoa. In addition, thioredoxin-like (Trx-like) proteins, which have similar structures and spatial topology to Trxs, belong to a group of thioredoxin-related proteins (TRPs) that is itself included in the Trx superfamily (Carvalho et al. 2006). Trx-like1, also known as TRP32, contains a Trx domain with a conserved CXXC active site (Lee et al. 1998), and human Trx-like1 is localised in the cytoplasm (Jiménez et al. 2006). Trxs serve an antioxidant function and have been studied extensively through both genetic and molecular approaches. For example, Trx-like1 participates in various redox reactions via the reversible oxidation and reduction of the two cysteine residues in its active site (Lee et al. 1998). In mice, overexpression of Trx protects against miscellaneous disease phenotypes associated with oxidative stress (Zhou et al. 2009; Widder et al. 2009). Similarly, the loss of $\operatorname{Tr} x-2$ in Drosophila was recently shown to exacerbate oxidative stress-dependent phenotypes (Tsuda et al. 2010).

Although Trx has been widely studied because of its antioxidant properties, reports focusing on the Trx-like proteins are limited, particularly in insects. The Chinese honeybee (Apis cerana cerana) is a major subspecies of $A$. cerana that is more resistant to adverse conditions than other subspecies (Yang 2005), making it important for agriculture. Recently, the numbers of $A$. cerana cerana colonies have decreased, possibly due to oxidative stress caused by infectious diseases, UV light or global warming (Xu et al. 2009), and inappropriate management. Here, we cloned and characterised the Trx-likel gene from A. cerana cerana and evaluated its level of expression in various tissues and at various developmental stages. To determine the expression patterns in various oxidative stresses, we also investigated the oxidative stress response of AccTrx-likel at various temperatures and to injection of $\mathrm{H}_{2} \mathrm{O}_{2}$, after which we measured the activity of CAT and the concentration of MDA. This work provides valuable insight into the ability of Trx-likel to remove peroxides from A. cerana cerana under oxidative stress conditions.

\section{MATERIALS AND METHODS}

\subsection{Insect material}

A. cerana cerana at various stages of development (larvae, pupae and adult bees) were identified by age (Robinson 1992), eye colour (Rothenbuhler et al. 1952; Kerr and Laldlaw 1956) and cuticle pigmentation (Ziegler 1961). Bees were reared under artificial conditions in the experimental apiary of Shandong Agricultural University, Taian, China. Worker bees were collected in groups and kept in an incubator to induce oxidative stress. Adult bees 
were divided into five experimental groups, incubated at various temperatures $(4,15,25,34$ and $43{ }^{\circ} \mathrm{C}$, respectively) and collected at the indicated time points $(0.5,1,3,5$ and $7 \mathrm{~h})$. Tissues samples from the brain, muscle, honey sac, epidermis and midgut were quickly isolated from adult bees. All bees and tissues samples were flash-frozen in liquid nitrogen at the indicated time points and stored at $-80{ }^{\circ} \mathrm{C}$.

\subsection{Cloning and sequencing of AccTrx-like1 cDNA}

Total RNA was extracted from adult bees using TRIzol reagent (Invitrogen, Carlsbad, CA, USA) and incubated with RNase-free DNase I (Promega, Madison, WI, USA) to eliminate potential genomic DNA contamination. First-strand cDNA was synthesised from approximately $2 \mu \mathrm{g}$ of total RNA using reverse transcriptase (TransGen Biotech, Beijing, China). The full-length cDNA of AccTrx-likel was obtained using primers $\mathrm{Z} 1 / \mathrm{Z} 2$ via reverse transcription-PCR (RT-PCR) and with specific primers 3P1/3P2, B26/B25, 5P1/5P2 and AAP/AUAP via rapid amplification of cDNA ends-PCR (RACEPCR). All primer sequences are listed in Table I.

\subsection{Isolation of genomic DNA and the 5'- flanking region of AccTrx-like1}

Genomic DNA was prepared from adult bees using the EasyPure Genomic DNA Extraction Kit (TransGen Biotech, Beijing, China) with primers N11/N12, N21/N22 and N31/N32. Overlapping PCR fragments were amplified using specific primers $\mathrm{QP} 1 / \mathrm{QP} 2$ to isolate AccTrx-like1 genomic DNA. The genomic DNA was then digested with PstI at $37{ }^{\circ} \mathrm{C}$ overnight, followed by ligation with T4 DNA ligase (TaKaRa, Dalian, China). The ligation product was used as a template to obtain the $5^{\prime}$-flanking region via inverse polymerase chain reaction (IPCR) with the specific primers QDP1/QDP2 and QDP3/QDP4. We confirmed the sequence of the 5'-flanking region using the primers QDJ1/QDJ2 and analysed it using the TFSEARCH database (www.cbrc.jp/research/db/ TFSEARCH.html). Putative transcription factor binding sites (TFBS) were predicted in this 5 '-flanking region using the web software program MatInspector.

\subsection{Southern blot}

For Southern blot hybridisation, genomic DNA (30 $\mu \mathrm{g} / \mathrm{sample}$ ) from adult bees was completely digested with EcoRV, HindIII and XbaI for $48 \mathrm{~h}$ at $37{ }^{\circ} \mathrm{C}$ and then electrophoresed on a $1 \%$ agarose gel and transferred to Hybond- $\mathrm{N}^{+}$Nylon membrane (Amersham Pharmacia, England) by capillary blotting. The $\left[\alpha^{32} \mathrm{P}\right]$-radiolabelled probe was amplified using primers SB1/SB2 and the Primer-a-Gene Labelling System (Promega, Madison, WI, USA). Southern blot hybridisation was performed as described previously (Wang et al. 2010). Membranes were pre-hybridised overnight in blocking reagent and then incubated for $48 \mathrm{~h}$ at $65{ }^{\circ} \mathrm{C}$ with the gene-specific probe. After hybridisation, the membranes were washed twice in $\times 2 \mathrm{SSC}$ and $0.2 \%$ SDS followed by $\times 0.2 \mathrm{SSC}$ and $0.2 \%$ SDS for $10 \mathrm{~min}$ each at $42{ }^{\circ} \mathrm{C}$. The radioactive signal was visualised using a FLA-7000 phosphorimager (Fujifilm).

\subsection{Production, purification and western blot analysis of recombinant protein}

The cDNA fragment containing the full-length open reading frame (ORF) was obtained using primers YH1/YH2, excised using BamHI and SacI and cloned into a pET-30a(+) (Novagen, Darmstadt, Germany) vector that has been digested with the same restriction enzymes. The recombinant plasmid, pET-30a (+)-AccTrx-like1, was then transformed into E. coli BL21 (DE3). Protein expression was induced with $0.1 \mathrm{mM}$ isopropyl- $\beta$-D-thiogalactopyranoside (IPTG) for $8 \mathrm{~h}$ at $37^{\circ} \mathrm{C}$ at an optical density of $A_{600}$ $=1.5$, after which cultures were centrifuged at $5,000 \mathrm{rpm}$ for $10 \mathrm{~min}$ at $4{ }^{\circ} \mathrm{C}$. Supernatants were analysed by SDS-PAGE. AccTrx-like1 was purified using the MagneHis ${ }^{\mathrm{TM}}$ Protein Purification System (Promega, Madison, WI, USA). After purification, the protein $\left(100 \mu \mathrm{g} \mathrm{mL}^{-1}\right)$ was mixed with Freund's adjuvant and injected subcutaneously into white mice in order to generate specific antibodies. Western blot was carried out to confirm the specificity of the anti-AccTrx-like1 antibody. Protein samples were loaded on $12 \%$ SDSPAGE gels and blotted onto to a polyvinylidene difluoride membrane using a semi-dry transfer apparatus. The membrane was blocked with $5 \%$ bovine serum albumin diluted in TBS before incubation with 
Table I. The primers used in this study.

\begin{tabular}{|c|c|}
\hline Primer & Primer sequence \\
\hline \multicolumn{2}{|c|}{ For the cloning of the full-length cDNA } \\
\hline \multicolumn{2}{|c|}{ Internal fragment primers } \\
\hline $\mathrm{Z1}$ & 5'-GTGCGGGTACAAAATTGGTG-3' \\
\hline $\mathrm{Z} 2$ & 5'-GTTGTTGAAATTGGTGAGCC-3' \\
\hline \multicolumn{2}{|c|}{ 3'-RACE primers } \\
\hline $3 \mathrm{P} 1$ & 5'-CCAATTGCTTTGCGTTATGTG-3' \\
\hline $3 \mathrm{P} 2$ & 5'-CTGGTAGTGAAGTAACAAGGATTG-3' \\
\hline B26 & $5^{\prime}$-GACTCGAGTCGACATCGA(T) $)_{18^{-} 3^{\prime}}$ \\
\hline $\mathrm{B} 25$ & 5'-GACTCGAGTCGACATCGA-3' \\
\hline \multicolumn{2}{|c|}{ 5'-RACE primers } \\
\hline $5 \mathrm{P} 1$ & 5'-GGGCATTGCACTAACTCC-3' \\
\hline $5 \mathrm{P} 2$ & 5'-CACCAATTTTGTACCCGCAC-3' \\
\hline AAP & 5'-GGCCACGCGTCGACTAGTACG(G) $)_{14-3}$ \\
\hline AUAP & 5'-GGCCACGCGTCGACTAGTACG-3' \\
\hline \multicolumn{2}{|c|}{ The full-length cDNA primers } \\
\hline QP1 & 5'-GCCGCCTTTCATGTTGTATTAAATC-3' \\
\hline QP2 & 5'-TTAATGACTTTCTCСТTTCTTACC-3' \\
\hline \multicolumn{2}{|c|}{ For the cloning of the genomic sequence } \\
\hline \multicolumn{2}{|c|}{ Intron 1 primers } \\
\hline N11 & 5'-GTGCGGGTACAAAATTGGTG-3' \\
\hline N12 & 5'-GGGCATTGCACTAACTCC-3' \\
\hline \multicolumn{2}{|c|}{ Intron 2 primers } \\
\hline $\mathrm{N} 21$ & 5'-GGAGTTAGTGCAATGCCC-3' \\
\hline $\mathrm{N} 22$ & 5'-GTTCATCACATTCACTTTCC-3' \\
\hline \multicolumn{2}{|c|}{ Intron 3 primers } \\
\hline N31 & 5'-GGAAAGTGAATGTGATGAAC-3' \\
\hline N32 & 5'-CACATAACGCAAAGCAATTGG-3' \\
\hline \multicolumn{2}{|c|}{ For the cloning of the promoter region } \\
\hline \multicolumn{2}{|c|}{ IPCR primers } \\
\hline QDP1 & 5'-CACCAATTTTGTACCCGCAC-3' \\
\hline QDP2 & 5'-GGAGTTAGTGCAATGCCC-3' \\
\hline QDP3 & 5'-CCACCAATTTTGTACCCGC-3' \\
\hline QDP4 & 5'-CCAAATGCAGTATTTCTTAAAG-3' \\
\hline \multicolumn{2}{|c|}{ The full-length promoter primers } \\
\hline QDJ1 & 5'-CTGCAGCTGACATCTCGCAATTTCG-3' \\
\hline QDJ2 & 5'-CACCAATTTTGTACCCGCAC-3' \\
\hline \multicolumn{2}{|c|}{ Primers used in constructing expression vector } \\
\hline \multirow[t]{2}{*}{ YH1 } & 5'-GGATCCGCCGCCTTTCATGTTG-3' \\
\hline & BamHI \\
\hline \multirow[t]{2}{*}{ YH2 } & 5'-GAGCTCGACTTTCTCCTTTCTTACC-3' \\
\hline & SacI \\
\hline
\end{tabular}


Table I. (continued).

\begin{tabular}{ll}
\hline Primer & Primer sequence \\
\hline Real-time PCR primers & \\
D1 & 5'-GGAGTTAGTGCAATGCCC-3' \\
D2 & $5^{\prime}$-GTTCATCACATTCACTTTCC-3' \\
$\beta$-actin1 & $5^{\prime}$-GTTTTCCCATCTATCGTCGG-3' \\
$\beta$-actin2 & $5^{\prime}$-TTTTCTCCATATCATCCCAG-3' \\
Primer used for probe synthesised & \\
SB1 & 5'GTGCGGGTACAAAATTGGTG-3' $^{\prime}$ \\
SB2 & $5^{\prime}$-GGGCATTGCACTAACTCC-3' \\
\hline
\end{tabular}

anti-AccTrx-like $1(1: 200)$ at $4{ }^{\circ} \mathrm{C}$ overnight. After washing with phosphate-buffered saline (PBS), the membrane was incubated with goat anti-mouse IgG (Dingguo, Beijing, China) conjugated to horseradish peroxidase (HRP), which was visualised with a chemiluminescent HRP substrate.

\subsection{Immunohistochemical analysis}

Adult bees were fixed with $4 \%$ paraformaldehyde overnight at $4{ }^{\circ} \mathrm{C}$. After being thoroughly washed in PBS, fixed samples were dehydrated with ethanol in a series of increasing concentrations, cleared in xylene and embedded in paraffin. Transverse sections $(10 \mu \mathrm{m})$ were prepared and mounted onto poly-Llysine-coated glass slides and then dewaxed. The sections were treated with $3 \% \mathrm{H}_{2} \mathrm{O}_{2}$ in the dark to quench any endogenous peroxidases. After antigen retrieval performed twice with $0.01 \mathrm{M}$ citrate (pH 6.0), the sections were blocked with $10 \%$ normal goat serum and incubated at $4{ }^{\circ} \mathrm{C}$ overnight with the anti-AccTrx-like1 serum (1:20) diluted in $10 \%$ normal goat serum. The following day, after washing in PBS, the sections were incubated at $37^{\circ} \mathrm{C}$ with HRP-conjugated goat anti-mouse $\operatorname{IgG}$ (Boster Biological Technology, Wuhan, China) and then with SABC Immunohistochemistry Kit (Boster Biological Technology, Wuhan, China) at $37{ }^{\circ} \mathrm{C}$. Colour development was performed using a DAB Horseradish Peroxidase Colour Development Kit (Boster Biological Technology, Wuhan, China). Immunolocalisation was observed using a light microscope. Negative controls were obtained by omitting the AccTrx-like1 antibody in the immunocytochemistry protocol.

\subsection{Experimental injections}

Prior to injection, the worker bees were placed on ice for $8 \mathrm{~min}$. Adult bees (around 5 days after emergence) were injected with $5 \mu \mathrm{L}$ of $\mathrm{H}_{2} \mathrm{O}_{2}\left(50 \mu \mathrm{M}\right.$ of $\mathrm{H}_{2} \mathrm{O}_{2}$ / worker) (Kim et al. 2011) or PBS (5 $\mu \mathrm{L} /$ worker) for the injection controls between the first and second abdominal segments, using a sterile needle. Untreated bees, $\mathrm{H}_{2} \mathrm{O}_{2}$-injected bees and PBS-injected bees were kept in cages, respectively, and they were all kept in an incubator with a controlled $60 \%$ relative humidity at $34{ }^{\circ} \mathrm{C}$ until collection at the appropriate time points. They were fed on the basic adult diet containing $30 \%$ honey from the source colonies and $70 \%$ powdered sugar and water.

\subsection{CAT activity assay and determination of MDA concentration}

CAT activity and MDA concentration were measured using commercially available assay kits (Institute of Biologic Technology of Nanjing Jiancheng, Nanjing, China). CAT activity was measured as the development of a yellow complex produced by the reaction between $\mathrm{H}_{2} \mathrm{O}_{2}$ and molybdenum-acid-nedymium. The amount of $\mathrm{H}_{2} \mathrm{O}_{2}$ decomposition in $1 \mathrm{~s}$ by $1 \mathrm{mg}$ protein was defined as 1 unit of CAT activity and expressed as units per milligramme protein. The absorbance was read at $405 \mathrm{~nm}$. MDA, a reliable indicator of lipid peroxidation, was measured using thiobarbituric acid (TBA). Stored post-treatment specimens were ground, weighed and immersed in $0.02 \mathrm{mmol} / \mathrm{L}$ Tris $-\mathrm{HCl}$ at a ratio of $1: 10$ (in milligrammes per millilitre). Tissue homogenates were then centrifuged at $4,000 \mathrm{rpm}$ for $10 \mathrm{~min}$, and the 
supernatants were transferred to a test tube. A standard solution was added to control test tubes, while distilled water was added to a blank test tube. After addition of TBA to each tube, samples were induced at $95{ }^{\circ} \mathrm{C}$ for $1 \mathrm{~h}$, cooled to room temperature and centrifuged at $4,000 \mathrm{rpm}$ for $10 \mathrm{~min}$. MDA concentration was expressed as nanomoles of MDA per milligramme protein (Yang et al. 2010), and absorbance was read at $405 \mathrm{~nm}$ using a spectrophotometer (Spectrumlab S22pc, China).

\subsection{Quantitative real-time $P C R$}

AccTrx-like1-specific primers D1/D2 were used to amplify a PCR product of $274 \mathrm{bp}$ and $\beta$-actin $1 / \beta$-actin2 primers were used to amplify an internal control gene fragment of $170 \mathrm{bp}$ from $A$. cerana cerana $\beta$-actin (GenBank ID: XM640276). The quantitative real-time PCR (qRT-PCR) reactions were carried out in triplicate in a total volume of $25 \mu \mathrm{L}$ using a $\mathrm{SYBR}^{\circledR}$ PrimeScript $^{\mathrm{TM}}$ RT-PCR Kit (TaKaRa, Dalian, China) according to the manufacturer's instructons. qRT-PCR was performed using a CFX96TM Real-time System (BioRad) with the following parameters: $95{ }^{\circ} \mathrm{C}$ for $30 \mathrm{~s}$, followed by 40 amplification cycles $\left(95^{\circ} \mathrm{C}\right.$ for $5 \mathrm{~s}, 53^{\circ}$ $\mathrm{C}$ for $15 \mathrm{~s}$ and $72{ }^{\circ} \mathrm{C}$ for $15 \mathrm{~s}$ ) and a melt cycle from 65 to $95{ }^{\circ} \mathrm{C}$. All analyses were based on the $\mathrm{CT}$ values of the PCR products. The qRT-PCR data were analysed with CFX Manager Software (version 1.1) to estimate the transcript copy numbers for each sample. AccTrxlikel expression levels were calculated using the $2^{-\Delta \Delta \mathrm{Ct}}$ comparative CT method (Livak and Schmittgen 2001). Data were represented as the triplicate mean \pm SD (standard deviation) and presented as the $n$-fold difference relative to $\beta$-actin gene expression. Statistical significance was determined by one-way ANOVA and a post-hoc Tukey's test using the Statistical Analysis System (SAS), version 9.1 (SAS Institute, Cary, NC, USA). Significance was defined as $P<0.05$. Three independent experiments were performed.

\section{RESULTS}

\subsection{Isolation and molecular characterisation of AccTrx-like1}

To explore the oxidative stress response of Trx-like1 in A. cerana cerana, we isolated the gene, designated AccTrx-likel (GenBank ID: JN699056), using RT-PCR and RACE-PCR. The full-length cDNA sequence of AccTrx-like1 consists of a 157 bp 5'-untranslated region (UTR) and a 600-bp ORF that encodes 287amino acid residues (a 3' UTR has not been isolated). The mature protein has a theoretical molecular mass of $31.5 \mathrm{kDa}$ and a deduced $\mathrm{p} I$ of 4.94, as calculated using the Compute $\mathrm{p} I / \mathrm{Mw}$ Tool (http://www.expasy.org/tools/ pi_tool.html). Figure 1a shows that the protein sequence is closely related to the sequences from Apis mellifera $(99.30 \%$ protein sequence identity), Drosophila melanogaster (64.93\% protein sequence identity), Bombyx mori (67.36\% protein sequence identity) and Nasonia vitripennis $(82.23 \%$ protein sequence identity). Furthermore, AccTrx-like1 contains a Trx domain with the conserved Cys- $X_{1} X_{2}$-Cys active site and four typical C-terminal proteasomeinteracting domains, characteristic of Trx-like (Figure 1a).

A phylogenetic tree of Trxs from various species was generated using a neighbour-joining method implemented in MEGA 4 to analyse the possible evolutionary relationships among Trxs. AccTrx-like1 clearly belongs to the Trx-like1 superfamily and it displays obvious differences from other characteristic Trx superfamilies, including Trx-1, Trx-2, Trx-3, Trx-like2 and Trx-like3 (Figure 1b). AccTrx-like1 is closely related to Trx-like1 from A. mellifera.

\subsection{Structural analysis of the genomic sequence of AccTrx-like1}

The full-length genomic sequence (no 3' UTR included; GenBank ID: JN699057) of AccTrx-likel is 1,987 bp and contains four exons separated by three introns, which is surprisingly similar to the structure of AmTrxlike1 (Figure 2a). Southern blot analysis was performed to determine the copy number of AccTrx-like1 in the A. cerana cerana genome. Genomic DNA was extracted from adult $A$. cerana cerana and individually digested with EcoRV, HindIII and XbaI. A specific region from the 5' end of the AccTrx-likel cDNA was 

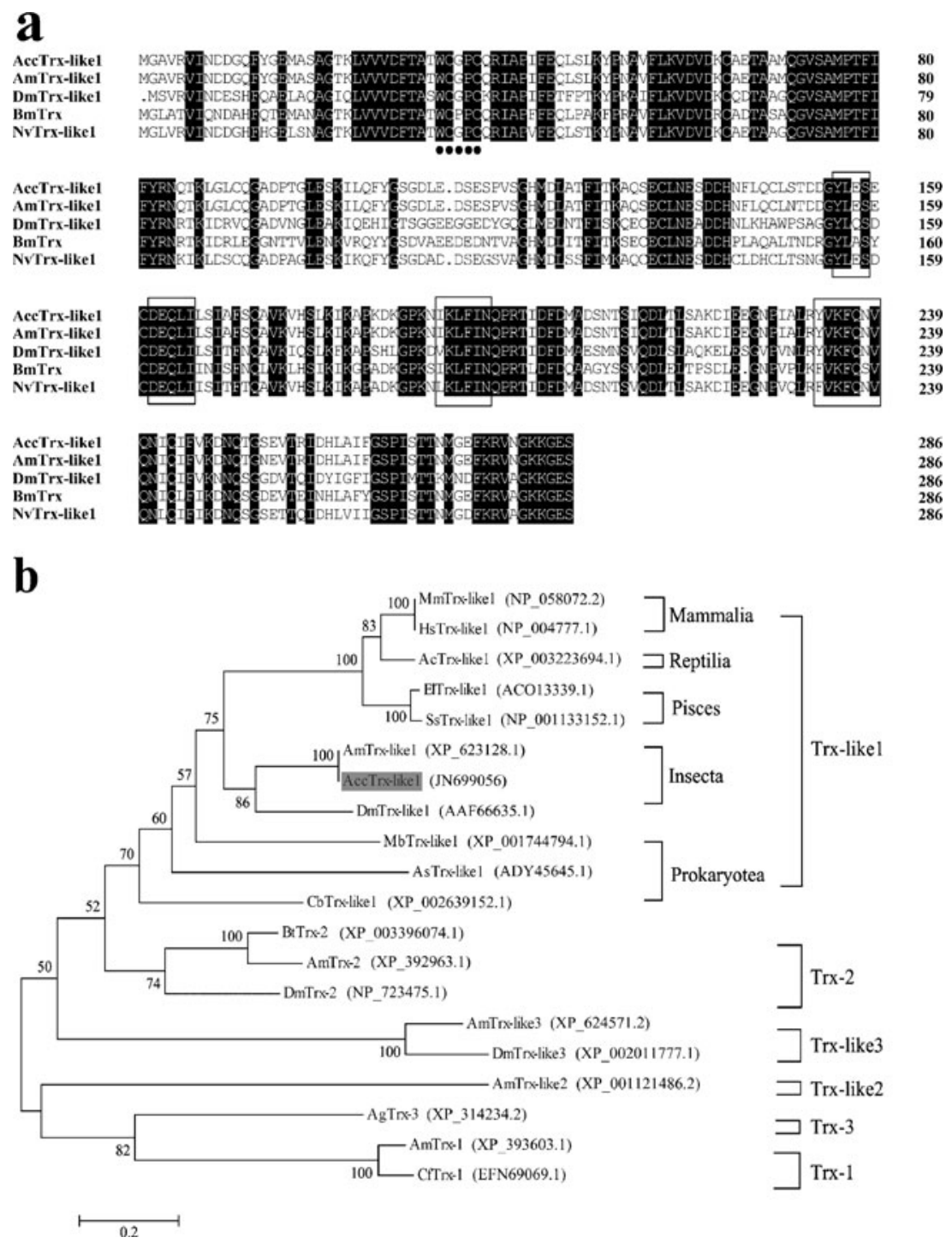

Figure 1. Characterisation of thioredoxins $(\operatorname{Tr} x s)$ from various species. a Multiple amino acid sequence alignment of AccTrx-like1 from A. cerana cerana, AmTrx-like1 (GenBank ID: XP_623128.1) from A. mellifera, DmTrx-like1 (AAF66635.1) from D. melanogaster, BmTrx (NP_001040348.1) from B. mori and NvTrx-like1 (XP_001608075.1) from N. vitripennis. The conserved Trx-like1 sequence motifs are boxed, and conserved sites are marked with a dot. b A phylogenetic tree of Trxs from several species was constructed using the neighbour-joining method. Six classes of proteins (Trx-like1, Trx-2, Trx-like3, Trx-like2, Trx-3 and Trx-1) and five categories (Mammalia, Reptilia, Pisces, Insecta and Prokaryotea) are shown on the tree. The scale bar represents 0.02-amino acid substitutions per site. Bootstrap values, provided at each node, are an indication of the reliability of each branch within the phylogenetic tree. A. cerana cerana is highlighted in grey. Each gene name is followed by the protein ID. The species of origin for each Trx is displayed by the abbreviation before the gene name: Mm Mus musculus, Hs Homo sapiens, Ac Anolis carolinensis, El Esox lucius, Ss Salmo salar, Am A. mellifera, Acc A. cerana cerana, Dm D. melanogaster, Mb Monosiga brevicollis, As Ascaris suum, Cb Caenorhabditis briggsae, Bt Bombus terrestris, Ag Anopheles gambiae, Cf Camponotus floridanus. 
a

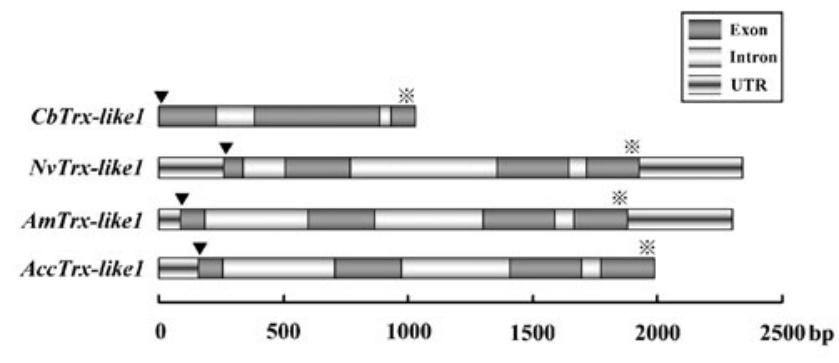

b

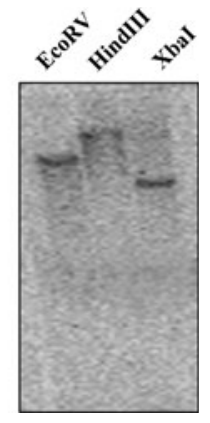

Figure 2. Schematic representation of Trx-like1 DNA structures and copy number analysis of the genomic sequence of AccTrx-like1. a Intron-exon structure of the Trx-likel gene from C. briggsae (CbTrx-like1, GenBank ID: XP_002639152.1), N. vitripennis (NvTrx-like1, GenBank ID: XP_001608075.1), A. mellifera (AmTrx-like1, GenBank ID: XP_623128.1) and A. cerana cerana (AccTrx-likē1, GenBank ID: JN699057). Exons are indicated by grey boxes and introns by light grey boxes. UTRs are displayed as striped boxes in this alignment. A 3' UTR has not been isolated from AccTrx-likel. The translation initiation (ATG) and terminal codons are marked by inverted triangles and reference marks, respectively. b Southern blot analysis of AccTrxlike1 from A. cerana cerana. Genomic DNA was completely digested with three restriction enzymes, EcoRV, HindIII and $X b a$ I. A single discrete band was detected in each lane using hybridisation with a specific probe.

isolated for use as a probe. After hybridisation, a single discrete band was detected in each lane of the Southern blot containing the three restriction digests (Figure 2b), indicating that there is a single copy of Trx-likel in the A. cerana cerana genome.

\subsection{Identification of the 5 '-flanking region of AccTrx-like1}

To study the organisation of the AccTrx-like 1 regulatory region, a 1,147-bp fragment upstream of the transcription start site was isolated by IPCR. Putative transcription factor binding sites (TFBS) were predicted in this 5 '-flanking region. Several interesting TFBS that have been studied in Drosophila are shown in Figure 3. There were 11 heat shock factor (HSF) binding sites related to heat-induced transcriptional activation (Fernandes et al. 1994) and four CF2-II sites related to the zinc finger DNA-binding domain protein family (Gogos et al. 1992). Three homeobox sites were found to be related to gene expression (Stanojević et al. 1989). Three sites were also found for Broad-Complex (BR-C), which is an ecdysone-responsive key regulator of metamorphosis (von Kalm et al. 1994). We identified one deformed (Dfd) binding site, which is related to the specificity of homeotic gene action (Ekker et al. 1992) and two crocodile (Croc) binding sites, which are related to brain development (Jeffrey et al. 2000). In addition, basic TATA and CAAT boxes were identified in the $5^{\prime}$-flanking region of the promoter (data not shown). The above listed transcription factor binding sites are, so far, only computationally predicted ones, based on sequence similarity. They have neither been validated statistically, nor experimentally.

\subsection{Expression patterns of AccTrx-like1 at various development stages and in various tissues}

To examine the stage- and tissue-specific expression of Trx-likel in A. cerana cerana, qRT-PCR assays was performed. Stage-specific expression analysis showed that the amount of AccTrx-likel mRNA increased rapidly from days 3 to 6 of larval development and then decreased from white- to pink-eyed pupae, reaching the lowest expression level in the adult stages. AccTrx-likel is therefore expressed at the highest level in larvae (Figure 4a). Various tissues were next extracted from adult bees; tissue-specific analyses indicated that high transcript levels are present in the epidermis and 


\begin{tabular}{|c|c|}
\hline $\begin{array}{l}\text { CTGCAGCTGACATCTCGCAATTTCGATATATCGAAATACAAATTGAGGAATATGCTC } \\
\text { HSF }\end{array}$ & -1091 \\
\hline AATAATCGACATATCGAAACTTATTGAACATAAATTCGAATCGTCAATTTGGAAAAG & -1034 \\
\hline $\begin{array}{c}\text { CTAAATTATAAGAGATCTTTTCAATCTTGTACGTAAATCAAAAAATATACAAATAAC } \\
\text { HSF } \\
\text { CF2-II }\end{array}$ & -978 \\
\hline GAATTGAATATACAAATAGACTTATTTAAGAAATAALINATATATATAATATGTAT & -920 \\
\hline ATGAATCGGTTATAATCTAACGATTTCCAACATGTGAATA HSFAAATAAAAAAAATA & -863 \\
\hline $\begin{array}{c}\text { Dfd } \\
\begin{array}{c}\text { TATATTAATAATTTTATTAAAATCTTACCACATTTGAATGAATATTGAATGAATA } \\
\text { HSF }\end{array} \\
\text { HSF }\end{array}$ & -806 \\
\hline TATGdAGAAACATTCAAAGCTATCCCGCTTTCGAAATCCAATCAAATGATAATTTA & -749 \\
\hline $\begin{array}{l}\text { CACAACGATAAAAGTTTAAAACACTATTCAAATCAAATTTAGTGTAATAACTAAGTT } \\
\text { BR-C }\end{array}$ & -692 \\
\hline $\begin{array}{l}\text { AAATAAACACATATTAATTAAACAGAGCTTAATAATTTTTATTTATAACCGTAATAT } \\
\mathrm{Hb}\end{array}$ & -635 \\
\hline AATAATCTATCAATAAAAATTTTACGTAATTACACACAACTGGTAAAATGCGACTTG & -578 \\
\hline TCACCACAATTTTAATTCTATACTGACATCATGCGCATTATGATGCGCAATGATTCA & -521 \\
\hline $\begin{array}{l}\text { TTTTGCTAAATCTTAGCAATCTTTTGATTGGTTAAAATTGTTTCTCCATTTTCTTAT } \\
\text { HSF }\end{array}$ & -464 \\
\hline TTAATCCGCGCGAAAATTAAACTATTATATAATATATTTTAATTATGAATTCCAATT & -407 \\
\hline GCACACATTAAAAAATTCCAATTGCACACATTAAAAAATTAAATTAATGTTTCTTCA & -350 \\
\hline $\begin{array}{l}\text { TTTCAATTATCAAATTATAATTTATTTTAAATTATAATTTTTAATAAGAGGAAGAAT } \\
\text { HSF }\end{array}$ & -293 \\
\hline $\begin{array}{l}\text { GAACTCGATTCGATGA } \frac{\text { AGAAATTCAAATATGTTGAACATGAATGCAAATTTTAATTT }}{\mathrm{Hb}} \text { HSF Croc }\end{array}$ & -236 \\
\hline $\begin{array}{l}\text { TTATAAAAAGATATACGATAAAAAATATTTTCATATCTCGAACATAATATAGAAAAA } \\
\text { BR-C }\end{array}$ & -179 \\
\hline $\begin{array}{ll}\text { ATAAATATAATATAAATAATTTAAATAAATAATAAGACAAATAAATAATACAAATAA } \\
\text { Croc } & \text { HSF } \\
\end{array}$ & -122 \\
\hline $\begin{array}{l}\text { ATAAATATTTAGAAAAAAATTTAGAAAATAAATTTAAGTCGCATTTTCATATATTCT } \\
\text { CF2-II }\end{array}$ & -65 \\
\hline AGCATTAGTTGCATTTTCAATTCATCCAGCTATTTTATATATAAAGTGCTTTCATGT & -8 \\
\hline AAGTTTCCAA: & +10 \\
\hline
\end{tabular}

Figure 3. Characterisation of the 5'-flanking region in AccTrx-likel. The transcription start site is indicated with an arrowhead. The predicted transcription factor-binding sites mentioned in the text are marked as follows: $H S F, C F 2-I I, D f d$ and BR-C sites are boxed, $\mathrm{Hb}$ sites are highlighted in light grey and Croc sites are highlighted in grey.

the brain. These results suggest that AccTrxlikel functions in early development and that it is primarily expressed in epidermis and brain.

\subsection{Localisation of AccTrx-like1}

To provide further insight into the role of AccTrx-like1, we next measured protein expression. SDS-PAGE analysis revealed a molecular mass of approximately $31 \mathrm{kDa}$ for the recombinant protein, which was purified using the MagneHis ${ }^{\mathrm{TM}}$ Protein Purification System (Figure 5a). We used western blot analysis to determine the specificity of the anti-AccTrxlike1 antibody and observed a single band at approximately $31 \mathrm{kDa}$ (Figure 5b), indicating that the anti-AccTrx-like1 antibody is reasonably specific.

To determine the localisation of AccTrx-like1 in epidermis and brain, immunohistochemistry was performed on paraffin sections from adult bees, using the anti-AccTrx-like1 antibody. The results revealed that expression of AccTrx-like1 is primarily localised to the median calyx of the mushroom bodies, the centre body, the surrounding regions of the antennal lobe (al) and 

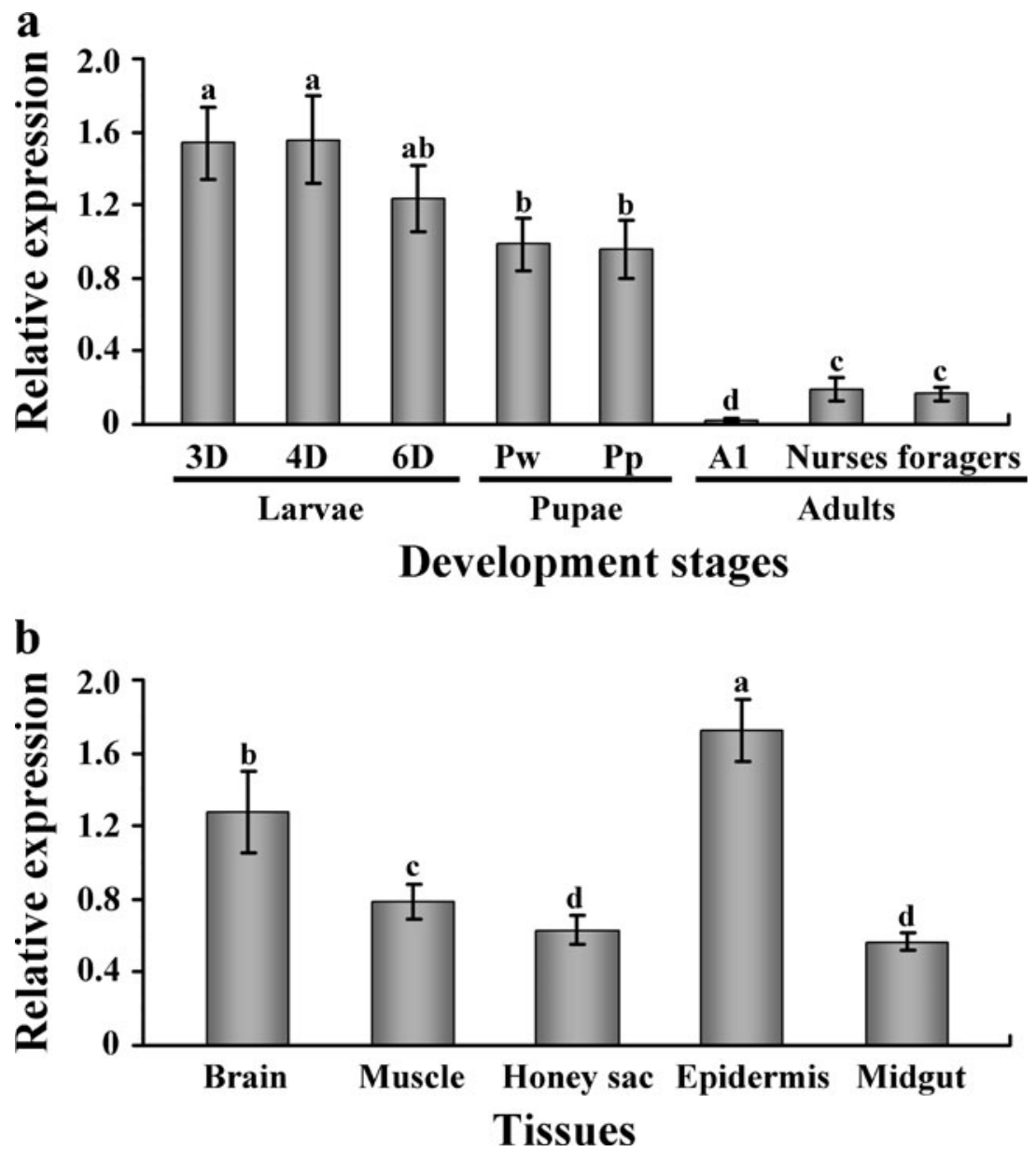

Figure 4. Expression patterns of AccTrx-likel at various developmental stages and tissues. a The distribution of AccTrx-like1 transcripts at various developmental stages: larvae on day s 3, 4 and 6; successive pupal stages including pupae with white $(P w)$ and pink $(P p)$ eyes; adults on day $1(A 1)$, nurses and foragers. b AccTrx-like1 expression patterns in the brain, muscle, honey sac, epidermis and midgut, with the $\beta$-actin gene shown for comparison. Vertical bars represent the means \pm SEM $(n=3)$. Letters above the bars designate significant differences $(P<0.05)$.

the lobula (lo) and medulla (me) of the optic lobes. Epidermis contained broadly expressed AccTrx-like1 (Figure 5c).

\subsection{Expression of AccTrx-like1 at various temperatures}

To assess the influence of temperature on the expression of AccTrx-like1, we divided the insects into five groups. We analysed the effect of temperature, with $34{ }^{\circ} \mathrm{C}$ representing hive tem- perature as the control setting. Heat shock $\left(43^{\circ} \mathrm{C}\right)$ and indirect chilling injuries (4 and $15^{\circ} \mathrm{C}$ ) are considered to be main functional injuries (Yocum et al. 1994). As shown in Figure 6, AccTrx-like1 expression was induced by shifts to temperatures between 4 or $25^{\circ} \mathrm{C}$ within $0.5 \mathrm{~h}$ and peaked at $15{ }^{\circ} \mathrm{C}$. Extended incubation at low temperatures increased the expression of AccTrx-like1, which was up-regulated by 3 - or 7 -h incubation at $4{ }^{\circ} \mathrm{C}$ and 1-, 5- or 7-h incubation at $15{ }^{\circ} \mathrm{C}$. Interestingly, high temperatures $\left(43{ }^{\circ} \mathrm{C}\right)$ did not result in 

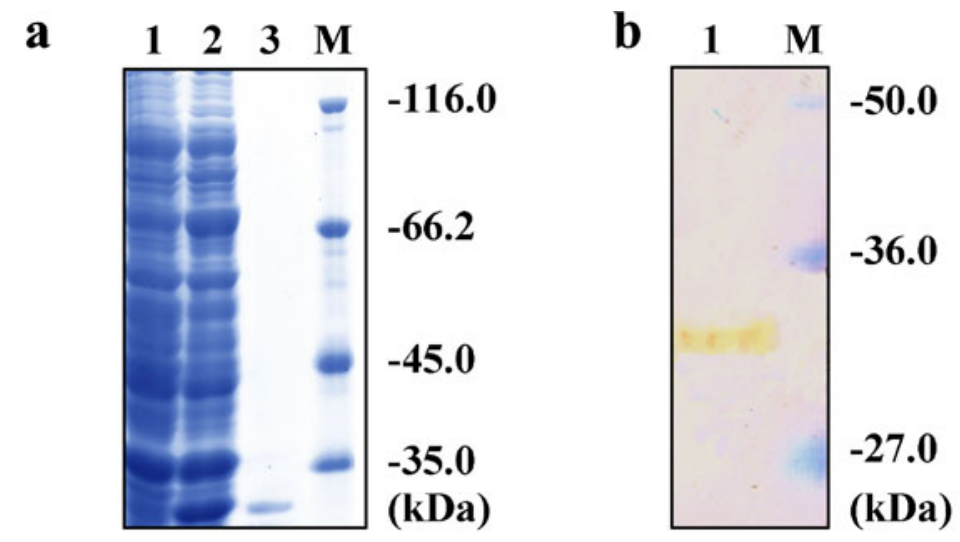

c brain epidermis

AccTrx-like1
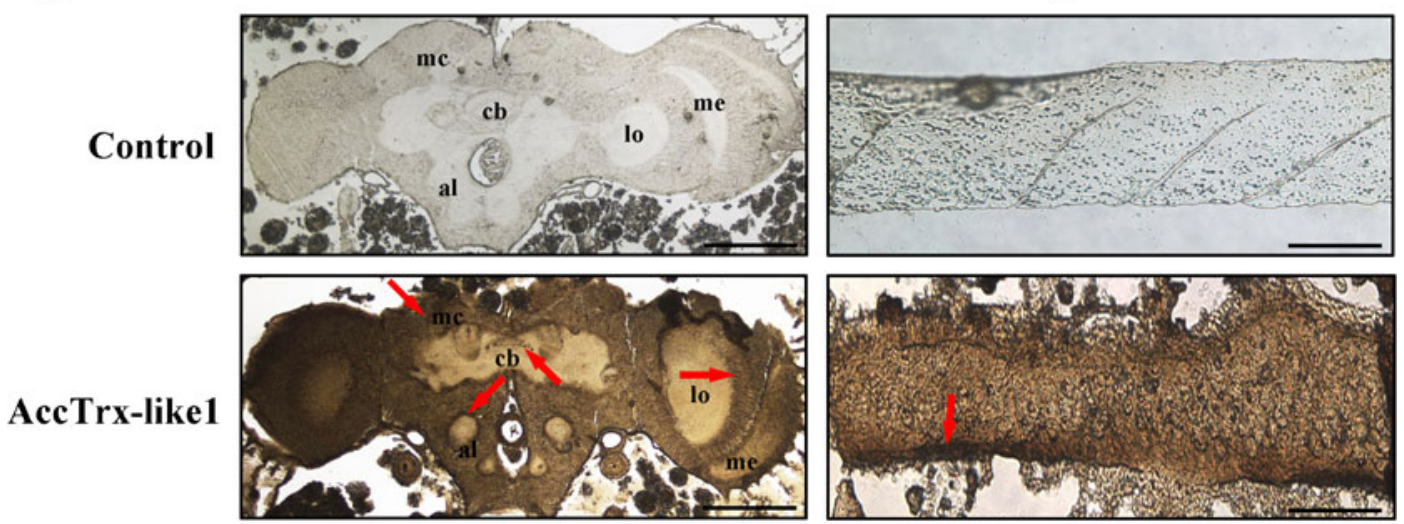

Figure 5. Overexpression, purification, western blot and immunohistochemistry analysis of AccTrx-like1. a Expression and purification of AccTrx-like1 protein, as shown by SDS-PAGE. Lane 1, non-induced expression of recombinant AccTrx-like1 protein; lane 2, overexpression of recombinant AccTrx-like1 protein after IPTG induction; lane 3, purified recombinant AccTrx-like1 protein and lane $M$, protein molecular weight marker. b Western blot analysis showing specificity of the anti-AccTrx-like1 antibody. Lane 1, the specific anti-AccTrxlike1. Lane $M$, pre-stained protein molecular weight marker. c Immunohistochemistry analysis of AccTrx-like1 expression in the brain and epidermis of A. cerana cerana. Top, the negative control staining; bottom, the tissues reacted with the AccTrx-like1 antibody. The major regions of the brain are indicated with arrows as follows: $m e$ medulla, $c b$ centre body, $a l$ antennal lobe, lo lobula, $m c$ median calyx of the mushroom body. Scale bars, $500 \mu \mathrm{m}$.

up-regulation of AccTrx-like1 expression. We conclude that AccTrx-likel expression is induced by low temperatures, while high temperatures inhibit its expression.

\subsection{Expression profiles of AccTrx-like1 in response to oxidative stress}

To investigate the transcriptional expression profile of AccTrx-likel after $\mathrm{H}_{2} \mathrm{O}_{2}$ injection, $A$. cerana cerana worker bees were injected with $\mathrm{H}_{2} \mathrm{O}_{2}$, and RNA samples were prepared at various time points. We used qRT-PCR to analyse changes in the transcription of AccTrxlikel induced by $\mathrm{H}_{2} \mathrm{O}_{2}$ injection. As shown in Figure 7a, the mRNA levels of the AccTrx-like1 were increased $30 \mathrm{~min}$ after $\mathrm{H}_{2} \mathrm{O}_{2}$ injecting compared with control. Expression then decreased from 45 to $180 \mathrm{~min}$, with the lowest level of expression occurring at $120 \mathrm{~min}$. 


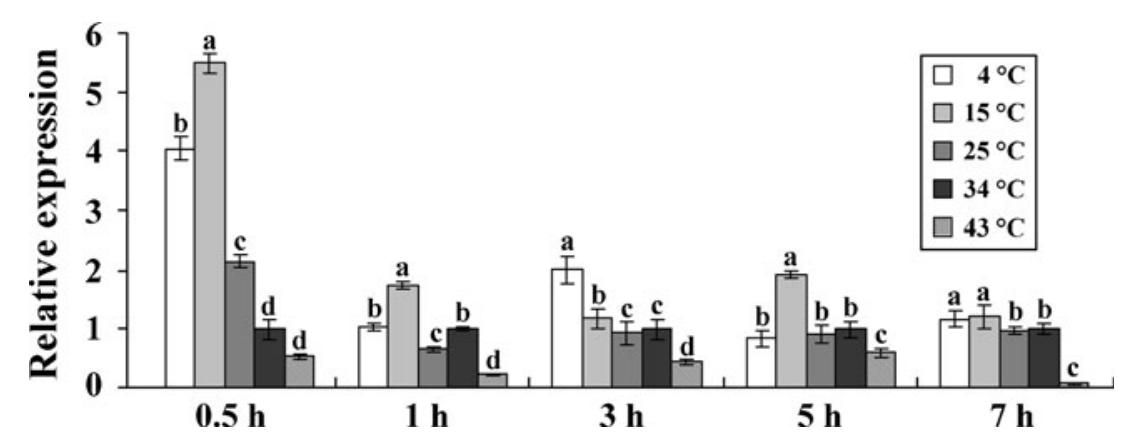

Figure 6. Expression patterns of AccTrx-likel after incubation at various temperatures $\left(4,15,25,34\right.$ and $\left.43{ }^{\circ} \mathrm{C}\right)$ for various lengths of time $(0.5,1,3,5$ and $7 \mathrm{~h})$ as measured by qRT-PCR. Expression of the endogenous control gene $\beta$-actin was used for normalisation. Note that $34{ }^{\circ} \mathrm{C}$ is the normal temperature for $A$. cerana cerana; therefore, it was considered the control temperature for each treatment. Vertical bars represent the means $\pm \operatorname{SEM}(n=3)$. Various letters above the bars designate significant differences $(P<0.05)$.

In order to determine whether $\mathrm{H}_{2} \mathrm{O}_{2}$ influences CAT activity in $A$. cerana cerana worker bees or whether AccTrx-likel possesses the ability to remove $\mathrm{H}_{2} \mathrm{O}_{2}$, we measured traditional oxidative stress parameters, including the activity of the antioxidant scavenging enzyme CAT and a highly toxic marker for lipid peroxidation, MDA (Yang et al. 2010; Del et al. 2005). MDA was assayed using TBA, and we measured CAT activity and MDA levels in vitro. As shown in Figure $7 \mathrm{~b}$, the MDA content increased within 15 min after $\mathrm{H}_{2} \mathrm{O}_{2}$ injection, declined at $30 \mathrm{~min}$, and then consistently increased until $180 \mathrm{~min}$. Figure $7 \mathrm{c}$ shows that the activity of CAT increased within 15 min after $\mathrm{H}_{2} \mathrm{O}_{2}$ injection and subsequently declined. We interpret these results to mean that MDA levels and CAT activity were both low at $30 \mathrm{~min}$, when the expression of AccTrx-likel was relatively high, indicating that AccTrx-likel plays an antioxidant role at $30 \mathrm{~min}$ post-injection.

\section{DISCUSSION}

Oxidative stress plays a role in many different disease processes and is characterised by depletion of general antioxidant systems, leading to alterations in the cellular redox state (Jiménez et al. 2006). The balance between ROS production and antioxidants determines the degree of oxidative stress (Finkel and
Holbrook 2000). Previous studies have demonstrated that members of the Trxs family are essential proteins directly related to the cellular antioxidant network (Gromer et al. 2004). In this work, we have described the sequence features and expression profile of AccTrx-like1. Clearly, AccTrx-like1 plays an important role during short periods of oxidative stress, particularly those related to low environmental temperatures.

Stage-specific expression analysis revealed that AccTrx-likel expression in the early larval stage is higher than that observed in adults. One explanation for this pattern is that other defensive systems are not yet fully developed in the larvae, making them more susceptible to diseases and other stressors (Figure 4a). Both biotic and abiotic factors can result in elevated levels of ROS, and insects have evolved a sophisticated response to oxidative stress. It is reasonable to assume that this defensive system takes time to mature and functions imperfectly at larval stages. Accordingly, there are many antioxidative genes that have been shown to respond to oxidative stress in vivo (Corona and Robinson 2006). When an organism is exposed to certain stimuli such as disease, the expression of these antioxidative genes may increase as a protective mechanism. Nevertheless, the adult bees are mainly subjected to abiotic stress especially the oxidative stress. Our findings imply that AccTrx-like1 may function earlier 
$\mathbf{a}$
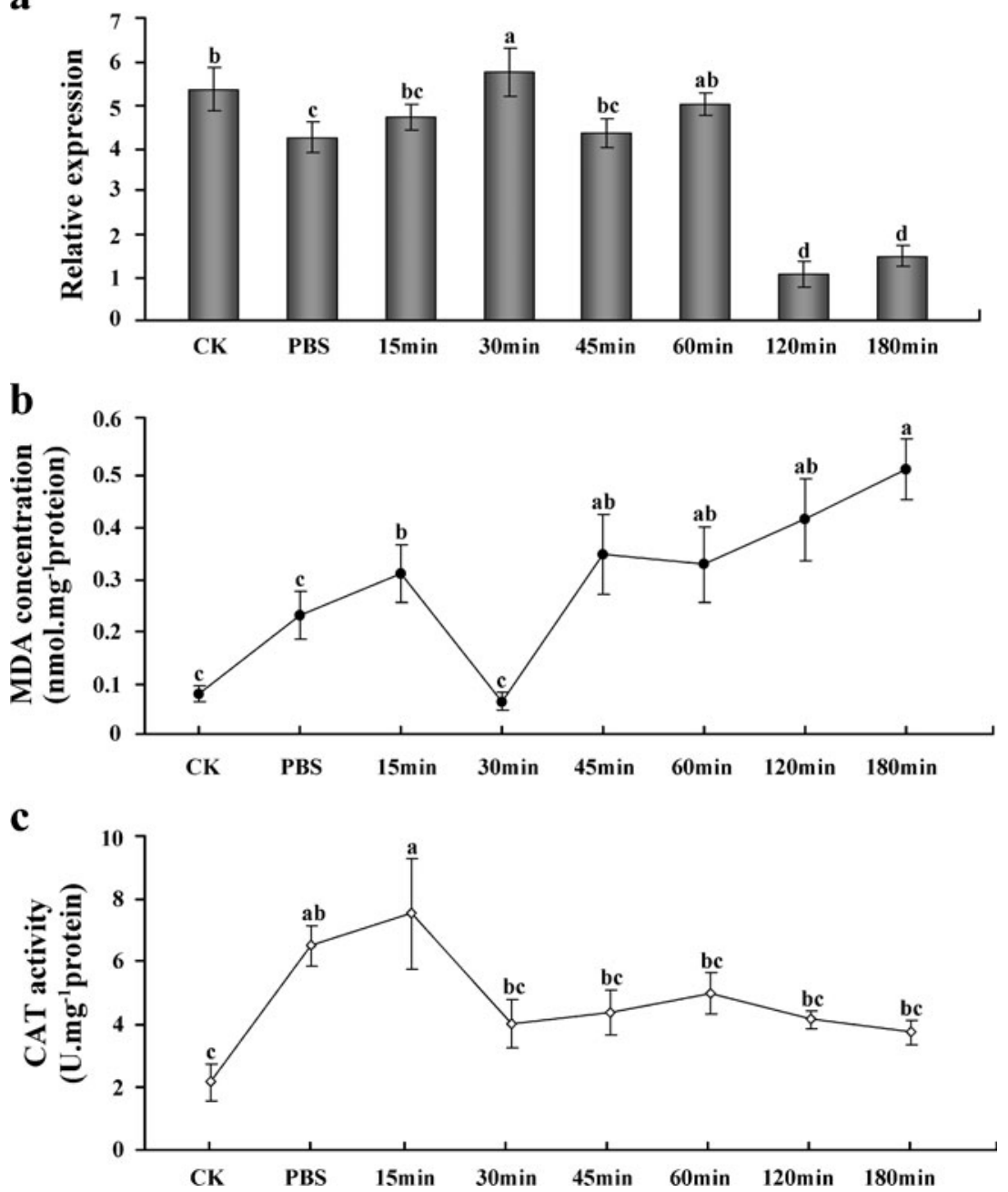

Figure 7. Expression patterns of AccTrx-likel induced by $\mathrm{H}_{2} \mathrm{O}_{2}$ overload and detection of MDA content and CAT activity. In all experiments, untreated $A$. cerana cerana worker bees were used as controls $(C K)$. A. cerana cerana worker bees injected with PBS were used as injection controls. a Induction of AccTrx-likel in worker bees was analysed by quantitative PCR, with the $\beta$-actin gene used for normalisation. b Effects of $\mathrm{H}_{2} \mathrm{O}_{2}$-induced stress on MDA concentration (in nanomoles per milligramme protein) in A. cerana cerana. c Effects of $\mathrm{H}_{2} \mathrm{O}_{2}$-induced oxidative stress on CAT activity (in units per milligramme protein) in A. cerana cerana. Vertical bars represent the means $\pm \operatorname{SEM}(n=3)$. Various letters above the bars designate significant differences $(P<0.05)$.

than other antioxidative genes. The expression of AccTrx-like1 was relative low in adults, which could be due to the mature defensive system and the sufficient protection provided by the adult epidermis. Although the overall expression of AccTrx-likel in adults was low, tissue-specific analysis revealed specific, local- ised AccTrx-likel expression (Figure 4b). The honeybee brain, which is important for organised social and behavioural patterns, is very sensitive to ROS (Ament et al. 2008; Rival et al. 2004). The epidermis bears the brunt of external attacks and thus could be important in resistance to external stressors, including oxidative stress 
(Marionnet et al. 2003). High expression of AccTrx-likel in these two tissues may further defend the honeybee against oxidative stress.

Many social insects maintain precise environmental conditions within their nests by controlling such parameters as relative humidity, temperature and carbon dioxide levels (Jones et al. 2005). These conditions are thought to be those that are optimal for normal development of the brood (McMullan and Brown 2006). Temperature has been identified as the dominant abiotic factor directly affecting herbivorous insects, and honeybee colonies maintain their brood nests between 33 and $36{ }^{\circ} \mathrm{C}$ (Kleinhenz et al. 2003). When living organisms are subjected to environmental stresses such as extreme temperatures, excessive ROS are generated. As shown in Figure 6, we observed that high temperatures suppressed expression at nearly every time point. The inhibition of expression by high temperatures may be due to the inactivation of AccTrx-like1 (Ikemoto 2005) and other antioxidant gene products. Because relatively low temperatures induced high expression of AccTrx-like1, we conclude that it is a cold-inducible gene. Low temperatures are harmful to insects (Michaud and Denlinger 2004) because they suppress flight metabolic rates and stimulate oxygen radical formation (Harrison and Fewell 2002). Therefore, A. cerana cerana benefits from being cold tolerant, and AccTrxlikel likely plays an important role in the antioxidant response to cold stress.

To further characterise the AccTrx-likel response to oxidative stress, $\mathrm{H}_{2} \mathrm{O}_{2}$ was used to stimulate oxidative stress-induced apoptosis (Hasnain et al. 1999). We examined the expression profiles of AccTrx-likel after $\mathrm{H}_{2} \mathrm{O}_{2}$ injection in worker bees. The results demonstrate that after $\mathrm{H}_{2} \mathrm{O}_{2}$ overload, AccTrx-likel expression is induced at early time points and then decreases over time. This result differs from those observed in response to temperature changes. AccTrx-likel appears to play an immediate antioxidant role as a result of short-time oxidative stress caused by $\mathrm{H}_{2} \mathrm{O}_{2}$, particularly at $30 \mathrm{~min}$ (Figure 7). In this study, because of the low CAT activity observed at $30 \mathrm{~min}$, MDA levels would be expected to increase. However, our results show that the MDA content was also low, suggesting that AccTrx-likel might be playing a critical role in the response to oxidative stress. At $30 \mathrm{~min}$, the activity of CAT was low due to inactivation of the enzyme. After bees were injected with $\mathrm{H}_{2} \mathrm{O}_{2}$, the antioxidant response was presumably activated resulting in the production many other enzymes designed to protect against oxidative stress and maintain the MDA concentration at a low level. Eventually, these antioxidative mechanisms become depleted as free radicals accumulate, lipid peroxides continue to degrade, and the level of MDA increases. $\mathrm{OH}^{-}$is one example of a ROS with active chemical properties, whose accumulation could result in oxidative injury. CAT serves to protect the organism by breaking down $\mathrm{H}_{2} \mathrm{O}_{2}$ into $\mathrm{H}_{2} \mathrm{O}$ and $\mathrm{O}_{2}$. After injection of $\mathrm{H}_{2} \mathrm{O}_{2}$, it is possible that $\mathrm{OH}^{-}$levels were not high enough to activate CAT but still caused damage to cells. In other words, $\mathrm{OH}^{-}$may inhibit CAT activity until the accumulation of ROS reaches a level sufficient to induce expression of CAT (Breusegem et al. 2001). In contrast, the expression of AccTrx-likel was inversely related to CAT activity at early time points, suggesting that AccTrx-likel might play a critical role in the response to short-time oxidative stress. Thus, when Chinese honeybees were exposed to $\mathrm{H}_{2} \mathrm{O}_{2}$ for short periods of time, the expression of AccTrx-like1 was induced, presumably to protect against oxidative stress (Figure 7).

Taken together, the results obtained in the present study indicate that AccTrx-like1 plays an antioxidant role in response to oxidative stress caused by short-term $\mathrm{H}_{2} \mathrm{O}_{2}$ exposure and low temperatures. These findings provide evidence for the importance of AccTrx-likel in the Chinese honeybee and should encourage additional work aimed at understanding this antioxidant gene.

\section{ACKNOWLEDGEMENTS}

This work was financially supported by the National Natural Science Foundation (No. 31172275) of China, China Agriculture Research System (No. CARS-45) and National Department Public Benefit Research Foundation (No. 200903006). 
Identification de la TXNL1 d'Apis cerana cerana et caractérisation de son activité anti-oxydante.

Apidae / PCR quantitative en temps réel / stress oxydatif / thiorédoxine-like protéine1

\section{Identifzierung des thioredoxin-like1 Gens von Apis cerana cerana und Charakterisierung seiner antiox- idanten Wirkung.}

Trx-like1 / Apis cerana cerana / quantitative Real-time PCR / oxidativer Stress

\section{REFERENCES}

Ament, S.A., Corona, M., Pollock, H.S., Robinson, G.E. (2008) Insulin signaling is involved in the regulation of worker division of labor in honey bee colonies. Proc. Natl. Acad. Sci. USA 105, 4226-4231

Breusegem, F.V., Vranová, E., Dat, J.F., Inzé, D. (2001) The role of active oxygen species in plant signal transduction. Plant Sci. 161, 405-414

Carvalho, A.P., Fernandes, P.A., Ramos, M.J. (2006) Similarities and differences in the thioredoxin superfamily. Prog. Biophys. Mol. Biol. 91, 229-248

Corona, M., Robinson, G.E. (2006) Genes of the antioxidant system of the honey bee: annotation and phylogeny. Insect Mol. Biol. 15, 687-701

Del, R.D., Stewart, A.J., Pelleqrini, N. (2005) A review of recent studies on malondialdehyde as toxic molecule and biological marker of oxidative stress. Nutr. Metab. Cardiovasc. Dis. 15, 316-328

Ekker, S.C., von Kessler, D.P., Beachy, P.A. (1992) Differential DNA sequence recognition is a determinant of specificity in homeotic gene action. EMBO J. 11, 4059-4072

Evans, J.D., Aronstein, K., Chen, Y.P., Hetru, C., Imtru, J.L., Jiang, H., Kanost, M., Thompson, G.J., Zou, Z., Hultmark, D. (2006) Immune pathways and defence mechanisms in honey bees Apis mellifera. Insect Mol. Biol. 15, 645-656

Fernandes, M., Xiao, H., Lis, J.T. (1994) Fine structure analyses of the Drosophila and Saccharomyces heat shock factor-heat shock element interactions. Nucleic Acids Res. 22, 167-173

Finkel, T. (2003) Oxidant signals and oxidative stress. Curr. Opin. Cell Biol. 15, 247-254

Finkel, T., Holbrook, N.J. (2000) Oxidants, oxidative stress and the biology of ageing. Nature 408, 239-247

Fridovich, I. (1978) The biology of oxygen radicals. Science 201, 875-880

Gogos, J.A., Hsu, T., Bolton, J., Kafatos, F.C. (1992) Sequence discrimination by alternatively spliced isoforms of a DNA binding zinc finger domain. Science 257, 1951-1954

Gromer, S., Urig, S., Becker, K. (2004) The thioredoxin system-from science to clinic. Med. Res. Rev. 24, 40-89

Halliwell, B., Gutteridge, J.M.C. (1984) Oxygen toxicity, oxygen radicals, transition metals and disease. Biochem. J. 219, 1-14

Harrison, J.F., Fewell, J.H. (2002) Environmental and genetic influences on flight metabolic rate in the honey bee, Apis mellifera. Comp. Biochem. Physiol. A Mol. Integr. 133, 323-333

Hasnain, S.E., Taneja, T.K., Sah, N.K., Mohan, M., Pathak, N., Sahdev, S., Athar, M., Totey, S.M., Begum, R. (1999) In vitro cultured Spodoptera frugiperda insect cells: model for oxidative stressinduced apoptosis. J. Biosci. 24, 13-19

Ikemoto, T. (2005) Intrinsic optimum temperature for development of insects and mites. Environ. Entomol. 34, 1377-1387

Jeffrey, P.L., Capes-Davis, A., Dunn, J.M., Tolhurst, O., Seeto, G., Hannan, A.J., Lin, S.L. (2000) CROC-4: a novel brain specific transcriptional activator of $\mathrm{c}$ fos expressed from proliferation through to maturation of multiple neuronal cell types. Mol. Cell. Neurosci. 16, 185-196

Jiménez, A., Pelto-Huikko, M., Gustafsson, J.A., Miranda-Vizuete, A. (2006) Characterization of human thioredoxin-like-1: potential involvement in the cellular response against glucose deprivation. FEBS Lett. 580, 960-967

Jones, W.D., Nquyen, T.A., Kloss, B., Lee, K.J., Vosshall, L.B. (2005) Functional conservation of an insect odorant receptor gene across 250 million years of evolution. Curr. Biol. 15, R119-R121

Kerr, W.E., Laldlaw, H.H. (1956) General genetics of bees. Adv. Genet. 8, 109-153

Kim, B.Y., Hiu, W.L., Lee, K.S., Wan, H., Yoon, H.J., Gui, Z.Z., Chen, S., Jin, B.R. (2011) Molecular cloning and oxidative stress response of a sigmaclass glutathione $S$-transferase of the bumblebee Bombus ignites. Comp. Biochem. Physiol. B Biochem. Mol. Biol. 158, 83-89

Kleinhenz, M., Bujok, B., Fuchs, S., Tautz, J. (2003) Hot bees in empty broodnest cells: heating from within. J. Exp. Biol. 206, 4217-4231

Laurent, T.C., Moore, E.C., Reichard, P. (1964) Enzymatic synthesis of deoxyribonucleotides. J. Biol. Chem. 239, 3436-3444

Lee, K.K., Murakawa, M., Takahashi, S., Tsubuki, S., Kawashima, S., Sakamaki, K., Yonehara, S. (1998) Purification, molecular cloning, and characterization of TRP32, a novel thioredoxin-related mammalian protein of $32 \mathrm{kDa}$. J. Biol. Chem. 273, 19160-19166

Livak, K.J., Schmittgen, T.D. (2001) Analysis of relative gene expression data using real-time quantitative PCR and the 2 (-Delta C (C)) method. Methods 25, 402-408 
Lopez-Martinez, G., Elnitsky, M.A., Benoit, J.B., Lee Jr., R.E., Denlinger, D.L. (2008) High resistance to oxidative damage in the Antarctic midge Belgica antarctica, and developmentally linked expression of genes encoding superoxide dismutase, catalase and heat shock proteins. Insect Biochem. Mol. Biol. 38, 796-804

Marionnet, C., Bernerd, F., Dumas, A., Verrecchia, F., Mollier, K., Compan, D., Bernard, B., Lahfa, M., Leclaire, J., Medaisko, C., Mehul, B., Seité, S., Mauviel, A., Dubertret, L. (2003) Modulation of gene expression induced in human epidermis by environmental stress in vivo. J. Invest. Dermatol. 121, 1447-1458

McMullan, J.B., Brown, M.J. (2006) Brood-cell size dose not influence the susceptibility of honey bees (Apis mellifera) to infestation by tracheal mites (Acarapis woodi). Exp. Appl. Acarol. 39, 273-280

Michaud, M.R., Denlinger, D.L. (2004) Molecular modalities of insect cold survival: current understanding and future trends. Int. Congr. Ser. 1275, 32-46

Miranda-Vizuete, A., Ljung, J., Damdimopoulos, A.E., Gustafsson, J.A., Oko, R., Pelto-Huikko, M., Spyrou, G. (2001) Characterization of Sptrx, a novel member of the thioredoxin family, specifically expressed in human spermatozoa. J. Biol. Chem. 276, 31567-31574

Rival, T., Soustelle, L., Strambi, C., Besson, M.T., Iche, M., Birman, S. (2004) Decreasing glutamate buffering capacity triggers oxidative stress and neuropil degeneration in Drosophila brain. Curr. Biol. 17, 599-605

Robinson, G.E. (1992) Regulation of division of labor in insect societies. Annu. Rev. Entomol. 37, 637-665

Rothenbuhler, W.C., Gowen, J.W., Park, O.W. (1952) Androgenesis with zygogenesis in gynandromorphic honeybees (Apis mellifera L.). Science 115, 637-638

Schwarze, S.R., Weindruch, R., Aiken, J.M. (1998) Oxidative stress and aging reduce COX I RNA and cytochrome oxidase activity in Drosophila. Free Radic. Biol. Med. 25, 740-747

Spyrou, G., Enmark, E., Miranda-Vizuete, A., Gustafsson, J. (1997) Cloning and expression of a novel mammalian thioredoxin. J. Biol. Chem. 272, 2936-2941

Stanojević, D., Hoey, T., Levine, M. (1989) Sequence specific DNA-binding activities of the gap proteins encoded by hunchback and Krüppel in Drosophila. Nature 341, 331-335

Tanaka, T., Hosoi, F., Yamaguchi-Iwai, Y., Nakamura, H., Masutani, H., Ueda, S., Nishiyama, A., Takeda, S., Wada, H., Spyrou, G., Yodoi, J. (2002) Thioredoxin-2(TRX-2) is an essential gene regulat- ing mitochondria-dependent apoptosis. EMBO J. 21, 1695-1703

Tsuda, M., Ootaka, R., Ohkura, C., Kishita, Y., Seong, K.H., Matsuo, T., Aigaki, T. (2010) Loss of Trx-2 enhances oxidative stress-dependent phenotypes in Drosophila. FEBS Lett. 584, 3398-3401

von Kalm, L., Crossgrove, K., Von Seggern, D., Guild, G.M., Beckendorf, S.K. (1994) The Broad-Complex directly controls a tissue-specific response to the steroid hormone ecdysone at the onset of Drosophila metamorphosis. EMBO J. 13, 3505-3516

Wang, M., Kang, M., Guo, X., Xu, B. (2010) Identification and characterization of two phospholipids hydroperoxide glutathione peroxidase genes from Apis cerana cerana. Comp. Biochem. Physiol. C Toxicol. Pharmacol. 152, 75-83

Widder, J.D., Fraccarollo, D., Galuppo, P., Hansen, J.M., Jones, D.P., Ertl, G., Bauersachs, J. (2009) Attenuation of angiotensin II-induced vascular dysfunction and hypertension by overexpression of thioredoxin 2. Hypertension 54, 338-344

Xu, P., Shi, M., Chen, X.X. (2009) Antimicrobial peptide evolution in the Asiatic honey bee Apis cerana. PLoS One 4, e4239

Yang, G.B. (2005) Harm of introducing the western honeybee Apis mellifera $\mathrm{L}$. to the Chinese honeybee Apis cerana F. and its ecological impact. Acta. Entomol. Sin. 3, 401-406

Yang, L.H., Huang, H., Wang, J.J. (2010) Antioxidant responses of citrus red mite, Panonychus citri (McGregor) (Acari: Tetranychidae), exposed to thermal stress. J. Insect Physiol. 56, 1871-1876

Yocum, G.D., Zdárek, J., Joplin, J.H., Lee Jr., R.E., Smith, C.D., Manter, K.D., Denlinger, D.L. (1994) Alteration of the eclosion rhythm and eclosion behavior in the flesh fly, Sarcophaga crassipalpis, by low and high temperature stress. J. Insect Physiol. 40, 13-21

Zhang, Y., Bao, R., Zhou, C.Z., Chen, Y. (2008) Expression, purification, crystallization and preliminary X-ray diffraction analysis of thioredoxin Trx1 from Saccharomyces cerevisiae. Acta Crystallogr. Sect. F Struct. Biol. Cryst. Commun. 64, 323-325

Zhou, F., Gomi, M., Fujimoto, M., Hayase, M., Marumo, T., Masutani, H., Yodoi, J., Hashimoto, N., Nozaki, K., Takagi, Y. (2009) Attenuation of neuronal degeneration in thioredoxin-1 overexpressing mice after mild focal ischemia. Brain Res. 1272, 62-70

Ziegler, I. (1961) Genetic aspects of ommochrome and pterin pigments. Adv. Genet. 10, 349-403 